\title{
USUÁRIOS E PÚBLICOS NAS PRÁTICAS DE PROFISSIONAIS DA INFORMAÇÃO
} E ÁREAS CORRELATAS ${ }^{1}$

\author{
Eliane Cristina de Freitas Rocha \\ Doutora em Ciência da Informação \\ Professora da Escola de Ciência da Informação - UFMG \\ prof.lili.rocha@gmail.com
}

\section{Resumo}

\begin{abstract}
Este artigo tem como objetivo apresentar como os profissionais atuantes em bibliotecas, instituições arquivísticas e museológicas, além de analistas de tecnologia da informação têm abordado seus usuários e públicos em suas práticas de trabalho. Foi realizada revisão bibliográfica sobre as práticas de trabalhos de tais profissionais e pesquisa de campo envolvendo entrevistas com seis atuantes em Arquivos públicos e outros sete em instituições museológicas. Por meio da análise de conteúdo das entrevistas realizadas, comparada com o estudo bibliográfico anterior, conclui-se que todos os profissionais abordam seus usuários por meio de práticas de mediação com diferentes nuances. É possível afirmar que as práticas de mediação cultural são realizadas e problematizadas sobretudo por profissionais atuantes em museus, enquanto que as práticas de mediação informacional e documentária enfatizadas por bibliotecários e arquivistas. Já as práticas de mediação de analistas de sistemas se distanciam da discussão das práticas de mediação cultural e documentária, prevalecendo a discussão sobre os processos da mediação da linguagem/negociação de significados relativos aos processos de construção de sistemas. As práticas de mediação explícita de treinamento de usuário estão presentes nas práticas de analistas de sistemas, bibliotecários e arquivistas, mas não são alvo de práticas nem de atuação de museus, em que as ações de mediação explícita são organizadas por ações educativas e culturais.
\end{abstract}

Palavras-chave: Mediação. Arquivista. Bibliotecário. Museólogo. Analista de Sistemas. Usuário. Público.

\section{INTRODUÇÃO}

Este trabalho é resultante de um longo processo de pesquisa que se iniciou no ano de 2011, com a escrita de um projeto de doutorado que versava sobre as abordagens dos usuários, no âmbito das práticas profissionais, por bibliotecários e analistas de tecnologia da informação. Naquela ocasião, e ainda hoje, é destacada a discussão sobre a interdisciplinaridade como constituinte da Ciência da Informação (CI), tendo em perspectiva as suas raízes na Biblioteconomia e Sistemas de Informação (CAPURRO, 2003). O campo de estudos de usuários da informação da CI parecia profícuo para apontar convergências entre as referidas disciplinas, pois a importância de práticas centradas nos usuários é primordial para o sucesso tanto de bibliotecas, em contexto de transformação pelo avanço das tecnologias digitais, quanto de sistemas e aplicativos computadorizados cada vez mais integrados ao cotidiano das pessoas (ROCHA, 2013).

Nesta direção, o campo de estudos de usuários da informação foi abordado como aquele em que poderia acontecer interlocução entre as áreas de Biblioteconomia e Sistemas

\footnotetext{
${ }^{1}$ A autora agradece o auxílio recebido do Programa Institucional de Auxílio de Pesquisa a Docentes Recém Contratados (ADCR) da UFMG para realização da pesquisa
} 
de Informação, com possíveis contribuições para a construção do conhecimento em CI. Foram realizadas 33 entrevistas, na tese (ROCHA, 2013) com 17 bibliotecários e 16 analistas de tecnologia da informação, atuando em diversos ramos. De maneira geral, notou-se poucos contatos entre os profissionais bibliotecários e analistas de tecnologia da informação em suas práticas de trabalho, e restritos à atuação na construção de sistemas de gestão de documentos (como os GEDs). Emergiu, ao longo de algumas entrevistas realizadas junto a bibliotecários, a importância da atuação deles em acervos que transcendem o formato bibliográfico, com necessidade de maior capacitação para lidar com documentos que podem ser arquivísticos ou museológicos.

Propus, então, o estudo "Usuários e públicos nas práticas profissionais de arquivistas e museólogos: estabelecendo contrastes dos estudos de usuários por arquivistas e museólogos em relação aos bibliotecários e analistas de sistemas". O objetivo da pesquisa foi levantar como os profissionais atuantes em instituições museológicas e arquivísticas têm abordado seus usuários e públicos para compará-los com as práticas já estudadas de bibliotecários e analistas de tecnologia da informação na tese (ROCHA, 2013). Tal levantamento permitiu visualizar diferenças de perspectivas e conceitos relativos aos usuários e públicos, que serão abordados em dois aspectos, nas duas seções seguintes a esta: aspectos ontológicos (quem são os usuários e públicos) e b) práticas de mediação (atividades realizadas pelos profissionais junto aos seus usuários e públicos).

\section{METODOLOGIA}

Este trabalho é de natureza qualitativa e descritiva, objetivando comparar as

2 Na tese (ROCHA, 2013), foram entrevistados 17 bibliotecários e 16 analistas de tecnologia da informação. Os resultados da atuação destes profissionais, presentes na tese, foram comparados aos profissionais atuantes em instituições museológicas e arquivísticas entrevistados no estudo atual. Para permitir a comparação das práticas dos profissionais atuantes em Arquivos e instituições museológicas com os profissionais bibliotecários e analistas de sistemas pesquisados perspectivas de profissionais analistas de tecnologia da informação e profissionais atuantes em bibliotecas, instituições arquivísticas e museológicas relativas aos seus usuários e públicos. Para proceder a descrição, em aspectos ontológicos (quem são os usuários) e do campo da prática (práticas de mediação), foi necessário realizar uma extensa revisão bibliográfica sobre o que é o usuário nos campos envolvidos no estudo (aspectos ontológicos) e também sobre as práticas relativas aos usuários (práticas de mediação). Os estudos da tese (ROCHA, 2013), e outras leituras, municiaram tal revisão, que foi ampliada e aprofundada em trabalhos sobre mediação nas áreas envolvidas, publicados ou em vias de publicação (ROCHA, 2016b; COSTA, ROCHA, 2018; OLIVEIRA, ROCHA, 2018). Além da revisão bibliográfica, foram realizadas entrevistas semiestruturadas com as mesmas questões norteadoras presentes no estudo da tese ${ }^{2}$ : quem são os usuários e públicos; quais atividades de treinamento são realizadas pelos profissionais; quais atividades de mediação (educativas ou culturais) são realizadas junto aos usuários e públicos; desafios profissionais. As entrevistas foram realizadas junto a treze profissionais atuantes em atividades de gerência ou mediação em instituições arquivísticas e equipamentos museais e culturais, escolhidos por sua renomada qualidade em suas práticas junto aos públicos, entre os anos de 2015 e 2016. O tempo de realização das entrevistas variou entre 36 minutos e duas horas. Os sujeitos participantes da entrevista foram treze, ao todo ${ }^{3}$. Seis entrevistados atuavam em Arquivos públicos estaduais e municipais no Brasil de diversas regiões brasileiras (norte, nordeste, sul e sudeste), em setores relacionados à difusão ou

na tese, as mesmas questões norteadoras da entrevista da tese foram propostas para os profissionais atuantes em instituições arquivísticas e museológicas da pesquisa que aqui se relata.

3 Foram treze entrevistados em instituições arquivísticas e museológicas no estudo atual. $\mathrm{Na}$ tese (ROCHA, 2013), outros 33 profissionais foram abordados (analistas de tecnologia da informação e bibliotecários). 
em cargos de direção: dois tinham formação em Arquivologia, três em História um na área de Ciências Sociais Aplicadas, os quais serão doravante identificados pela letra $\mathrm{E}$, seguida de um numeral (E1 a E6). Os outros sete atuavam em instituições museológicas e equipamentos culturais (na região norte, nordeste e sul brasileiras, além de uma instituição grega), e serão identificados pela letra $\mathrm{M}$, seguida de um numeral (M1 a M7). A formação dos profissionais atuantes nos equipamentos culturais e museais é diversificada: três são formados em Artes, outros em Educação e Letras, Jornalismo, Turismo e Antropologia (participantes M1 a M6, brasileiros), Antropologia e Museologia (participante grega). Os equipamentos foram escolhidos por receberem grande número de visitantes no seu país e, que por motivo de sigilo, não serão denominados: um museu de arte contemporânea, um museu de história natural, dois equipamentos culturais ${ }^{4}$, um museu histórico, um museu de ciências, museu de arqueologia. A natureza de todos os equipamentos culturais e museais participantes é pública, à exceção de um deles, que é uma organização social (O.S.). Por questões de acordo de sigilo e confidencialidade, aprovados no comitê de ética da instituição a que a autora é professora, quaisquer detalhes das falas que permitissem a identificação tanto do participante quanto do equipamento ou instituição envolvidos não serão apresentados.

As entrevistas realizadas junto aos profissionais foram transcritas e tiveram seu conteúdo analisado por meio da análise de conteúdo, mesmo procedimento adotado na tese anterior (ROCHA, 2013). Os resultados da reflexão teórica e empírica da pesquisa realizada serão apresentados nas duas próximas seções deste artigo, que versam sobre aspectos ontológicos do usuário e do público, e práticas de mediação empreendidas. Os caminhos e descaminhos dos possíveis

4 Embora recebam a denominação de equipamentos culturais, os dois equipamentos pesquisados constavam da lista de museus brasileiros do IBRAM. O nome não será divulgado por motivos de sigilo. Um dos equipamentos diálogos das abordagens do público, além das conclusões são discorridos em sequência.

\section{ASPECTOS ONTOLÓGICOS: QUEM SÃO OS USUÁRIOS PARA OS PROFISSIONAIS?}

$\mathrm{Na}$ Ciência da Informação, o usuário é, habitualmente, na perspectiva tradicional de estudos de usuários, aquele que está em relação com equipamentos informacionais para realização de algum trabalho que envolva o uso da informação, normalmente de fontes bibliográficas, no caso das bibliotecas e centros de documentação, ou o uso de documentos, como no caso das instituições arquivísticas (ROCHA, 2016b; ARAÚJO, 2017; CUNHA; AMARAL; DANTAS, 2015). $\mathrm{O}$ usuário é um sujeito pragmático que tem pressa para realizar algo direta ou indiretamente relacionado à informação (o uso da informação pode ser da ordem do conhecimento/saber, ação ou diversão). A visão do usuário, assim como a etimologia da palavra "usuário" aponta, é utilitarista: o usuário é um número e um meio para a realização de algum fim, nesta visão tradicional do campo, e dominante na prática de bibliotecários e analistas de sistemas pesquisados em ROCHA (2016a).

A terminologia usuário não tem o mesmo significado nos campos da Biblioteconomia e da tecnologia da informação. Os usuários de sistemas de informação digitais são aqueles que utilizam aplicativos digitais de diversas naturezas - como os aplicativos de produtividade para o trabalho tanto pessoais (planilhas, editores de imagem, som, etc.) quanto para empresas (sistemas ERP, por exemplo), incluindo os sistemas de recuperação da informação digitais (SRI) e sistemas de gestão de documentos (GED). Ao usar SRIs digitais, sistemas de informação digitais e produtos digitais em processos de recuperação da informação, o usuário apresenta information search behavior, mas pode também ser produtor de registros em repositórios digitais, numa aproximação à expressão producer (ROCHA, 2013, 2016a).

Os usuários de produtos interativos, por

culturais preserva a memória de uma manifestação regional musical (cultura imaterial), e outro a memória da navegação, além de abrigar um complexo turístico. 
outro lado, são aqueles que lidam com qualquer produto digital ou que tenha tecnologia digital embarcada para realizar tarefas cotidianas. A princípio, o uso de produtos interativos no cotidiano (como jogos eletrônicos, GPS, smart devices) pode ser visto como manifestação de práticas informacionais dos sujeitos ${ }^{5}$, ou práticas sociais que envolvem fluxos informativos entre os sujeitos entre si e deles com os dispositivos técnicos.

A área do campo de estudos de usuários da Biblioteconomia e CI não problematiza especialmente o usuário como leitor $\mathrm{e}$ as atividades de leitura, reduzindo-o às dimensões do uso e consumo da informação, como usuário da informação e de serviços de bibliotecas e centros de documentação. Questões de apropriações e produção de bens culturais passam ao largo das discussões, apesar da construção do leitor ou do cidadão aparecer como problemática nas falas de bibliotecários atuantes na biblioteca escolar e pública (ROCHA, 2013, 2016a).

Já na área de tecnologia da informação, os usuários dos sistemas e aplicativos digitais são tomados como trabalhadores ou público consumidor. Os trabalhadores são aqueles usuários de sistemas ou aplicativos que servem para o exercício de atividades de trabalho em empresas ou instituições, tais como sistemas corporativos de recursos humanos, compras, entre outros. Já o usuário como público consumidor é tido como uma tendência no mercado de TI: são aqueles que se utilizam de aplicativos no cotidiano que servem para amplo espectro de atividades, tanto as profissionais quanto voltadas ao entretenimento e lazer. Para este caso, o usuário se converte em público, em uma definição de público relacionada à audiência ou ao alvo de ações mercadológicas (ROCHA, 2013). Usuários do Facebook ou do Whatsapp, por exemplo, são, sem sombra de dúvidas usuários dos aplicativos, mas também público

5 Araújo (2017) advoga em favor do estudo das práticas informacionais para entendimento das práticas informacionais como práticas culturais. Esta visão iria além de considerar a visão tradicional dos usuários dominante na prática de bibliotecários e analistas de TI (ROCHA, 2013) e também além da visão subjetivista do usuário.

6 Para Zago e Wada (2013, p. 277), stakeholders são "diversos grupos ou indivíduos que influenciam consumidor deles, e alvo de ações mercadológicas de tais empresas.

O público pode ser compreendido como parte da população de referência de ações mercadológicas, mas também de ações culturais e educativas. Ele pode ser segmentado, já que uma das definições de público justamente compreende o público como audiência, como alvo, indiferenciado, sem organização coletiva, e as pessoas que o formam tem em comum estarem sintonizadas em um mesmo canal de televisão, consumirem o mesmo produto, assistirem um mesmo espetáculo (GUARESCHI, 2009), podendo constituir uma multidão ou uma massa, no último caso. É possível segmentar o público por classe, faixa etária ou quaisquer outros propósitos para conseguir maior adesão para alguma ação, seja ela presença em algum evento, uso de algum aplicativo, etc. Na maior parte das vezes, o público é tido como passivo, embora seja uma tendência importante, do ponto de vista de atuação mercadológica, tê-lo como co-criador de valor, como parte interessada, como ativo, o que remete ao conceito de stakeholder ${ }^{6}$ (MOREIRA, 2007; ZAGO; WADA, 2013).

O público não é o coletivo organizado. Coletividades que se organizam em torno de uma causa podem constituir movimentos sociais. Grupos organizados " [...] na ordem do ser [...] por uma participação profunda dos membros do grupo" formam comunidades (GUARESCHI, 2009). A atuação de bibliotecários e analistas de sistemas não aponta trabalhos com coletivos organizados, seja por movimentos sociais ou comunidades. Esta perspectiva de atuação junto a comunidades organizadas apareceu muito timidamente na fala de uma bibliotecária atuante em biblioteca pública (ROCHA, 2013), associada ao entorno territorial com

ou podem ser influenciados por uma organização". A premissa é de que as organizações procurem atuar junto aos seus stakeholders para criação e agregação de valor de maneira customizada. $\mathrm{O}$ cliente existe, mas ele não é passivo, e não apenas recebe os produtos, mas pode ser incluído em estratégias de criação de experiências únicas na relação com as organizações e seus serviços. 
problemas sociais onde atuava. A problematização sobre as comunidades é ausente para os profissionais da tecnologia da informação entrevistados (ROCHA, 2013), embora a discussão sobre o letramento digital esteja presente.

Todos os profissionais entrevistados de equipamentos museais ou culturais pesquisados também problematizam, uns mais, outros menos fortemente, de maneira mais destacada do que os demais perfis de profissionais (arquivistas, bibliotecários, analista de TI), as relações estabelecidas por sua instituição com a comunidade:

esse museu está no entorno de umas das maiores e mais pesadas comunidades [da cidade...] e a gente tem um trato super perto com a comunidade e muito antigo né?! porque esse museu tem já 25 anos e esse link com a comunidade e o museu foi feito desde o começo, de fato a maioria das pessoas que trabalham aqui [...], começaram de crianças bem pequenas, inseridas da comunidade $e$ esse vínculo faz com que essas pessoas tenham hoje em dia não só uma formação universitária, mas uma formação pós né?! e inclusive mestrado tudo fornecido e ajudado pelo museu então é uma alavanca assim, inclusive. [M5].

A dinâmica dos públicos de cultura aparece nas falas dos profissionais dos equipamentos museais e culturais próximos à definição dos públicos da cultura: “[...] coalizões e agrupamentos efêmeros, fenômenos particulares da vida coletiva, diferentes de fazer parte de multidão ou associação [...] organismo vivo que se forma e se desfaz, composto por grupos sociais diferentes a cada período" (KÖPTCKE, 2012, p. 219). Para os profissionais atuantes nos equipamentos museais e culturais, o público é o visitante, que se faz e se desfaz, com variações conforme o dia da semana, se é dia de visita gratuita ou não, se é feriado ou não, se é fim de semana ou meio de semana: público de classe socioeconômica mais baixa tende a ir em dias de visita gratuita ou domingos, e precisaria ser educado em noções conservação, de maneira geral. O público dos eventos e exposições também varia bastante conforme o evento, a exposição: o público de atrações de música e dança popular, gratuitas, são de classe mais baixa. Há o público local e o público turista, exigindo diferentes atividades de mediação.

Nas instituições arquivísticas, emergiu também, diferentemente de Garcia Belsunce (1980), a categoria de público, essencialmente associada às ações educativas voltadas para $\mathrm{o}$ público escolar. Alguns entrevistados relatam práticas de aproximação da instituição com escolas, promovendo ações para conhecer o Arquivo e explorar a história da cidade. Tal público foi citado como de ensino fundamental nas entrevistas realizadas. Também as universidades são parte do público das ações educativas, por meio de trabalhos que apresentam a instituição para cursos de graduação em Arquivologia e História, por exemplo (visitas guiadas, por exemplo).

Além do público de ações educativas, algumas instituições arquivísticas ampliam sua atuação para o seu entorno geográfico, promovendo ações culturais (concertos, palestras, exposições). Em síntese, uma entrevistada apresenta a visão de usuário e público para a instituição arquivística em que trabalha:

"A gente vai ter enquanto usuários, vai ter o
pesquisador, o cidadão, que é aquele que vem
requerer suas cópias autenticadas que é o
que a gente fornece aqui, e tem [...] esse
público mais [...] voltado pra essa parte mais
cultural do Arquivo, que são as visitas
guiadas e as oficinas" (E1).

Já dentre os profissionais atuantes nos equipamentos culturais e museais, não se observou menção ao termo usuário em suas falas. Se os profissionais atuantes em bibliotecas, instituições arquivísticas e analistas de TI não problematizam a dinâmica do público e da comunidade em sua relação, tal aspecto aparece destacado na literatura e na prática em museus e equipamentos culturais. $\mathrm{O}$ público é visto em diversas facetas em todos: é o público esporádico, espontâneo, passante (conforme denominação dos entrevistados); e o público escolar.

Um dos equipamentos voltados para a cultura imaterial não apenas classifica $o$ público em espontâneo ou escolar, mas 
também em público produtor daquela cultura imaterial:

"um museu que tem essa peculiaridade, porque o público, não é só o público da exposição [...]. A gente compreende, isso é unânime na equipe, assim, que o público mais especial, pra gente, é o público que faz [nome da manifestação cultural] ... [M6]".

Há, também, em algumas instituições, e de forma predominante, a presença de pesquisadores, de produtores de conhecimento científico ou histórico em suas áreas, correspondendo à função de pesquisa do museu, de maneira semelhante ao usuário pesquisador nas instituições arquivísticas. Os museus, neste caso, são produtores de conhecimento sobre o patrimônio, a cultura material e imaterial.

Nas instituições arquivísticas, o uso acadêmico é presente nas falas dos entrevistados no campo associado aos usuários denominados "pesquisadores", os quais realizam trabalhos de mestrado, doutorado, geralmente na área de História, mas também em outras áreas como Arquitetura ou Jornalismo, a depender das características dos documentos custodiados pela instituição. Em algumas instituições visitadas, $o$ acervo remetia à história de construção da cidade, com alto valor arquitetônico, municiando o interesse de pesquisadores desta área. $\mathrm{O}$ uso por jornalistas, por sua vez, teve relação com a abertura de documentos referentes ao período da ditadura, em alguns casos. Já o uso por acadêmicos da História foi citado e é habitualmente associado como o mais frequente uso para finalidades de pesquisa. Este perfil normalmente não vai à instituição apenas uma vez, estendendo sua permanência por dias, semanas, meses, seria um público quase "fidelizado" (E1).

No que diz respeito aos usuários de instituições arquivísticas, é possível distinguir, na fala dos participantes da pesquisa que os usuários são aqueles que se utilizam dos serviços prestados pela instituição arquivística, tais como serviços de consulta, emissão de certidões, serviços de protocolo, variando conforme a natureza da instituição, seus fundos, coleções e seu acervo. Habitualmente, eles se apresentam em três categorias, conforme os usos do Arquivo: uso acadêmico, uso prático e uso popular (GARCIA BELSUNCE, 1980).

O uso prático é presente em diversas falas, mas com diversidade de abordagens nas falas dos entrevistados. Alguns citam que grande parte das consultas do arquivo é para o cidadão requerer direitos, tais como certidões, o que seria uma finalidade prática:

\section{"[a finalidade muitas vezes] é ter um segundo passaporte" (E3).}

Por sua vez, não aparece nas falas o usuário "popular", há citação de genealogistas, de usuários turistas ou artistas (por características específicas do acervo da cidade). Também surgiram falas associadas a consultas por curiosidade.

Outros citam que parte dos usos realizados pelos usuários do Arquivo para finalidade prática é realizada por usuários da administração, por órgãos do governo, denominando-os como "usuários da administração", pessoas jurídicas (em contraste com os usuários pessoas físicas cidadãos e pesquisadores). Nenhum deles citou a terminologia "usuário interno" para denominar este perfil de usuário.

Nas falas dos entrevistados atuantes em Arquivos, não é recorrente considerar o usuário como o produtor documental. Um dos entrevistados problematizou que os produtores são usuários dos serviços do Arquivo porque precisam ser treinados e educados na gestão de documentos e nos princípios arquivísticos, sendo importante público para as ações educativas, e que muitas vezes é negligenciado:

[...] o setor de difusão é ativo. [...Tem a] editoria e a ação educativa. [...] $A$ ação educativa [...] era toda voltada para o público escolar [...], para o currículo escolar [...] para auxiliar no ensino de história. [...] Tinha conteúdo voltado para público infantil, fundamental, médio e tal [...]. Mas a gente é difusão de quê, exatamente? [...] Por que nós trabalhamos [só] com escolas, se nosso público é bem mais amplo? [...] Os 
funcionários [do Estado] não são educados do ponto de vista arquivístico [...], nós da ação educativa não temos nenhuma responsabilidade nisso? [...] Nós produzimos competência na área [de Arquivo] e [...] começamos a desenvolver alguns produtos para [...] descolar da historiografia [...], para tratar de conteúdo arquivístico [...] falando de aspectos diferenciados que o Arquivo tem para pesquisa [...], cursos sobre noções de Arquivo, contexto de produção. [...] Estamos tentando formatar um curso EAD para servidores. [Temos muitos servidores de protocolo no Estado. Tem experiência importante de escola de governo também] (E6).

Nas práticas profissionais de bibliotecários e analistas de TI pesquisados na tese (ROCHA, 2013), foram identificadas dificuldades em entender verdadeiramente quem é o usuário $\mathrm{e}$ quais são suas necessidades e comportamentos. Bibliotecários normalmente vêem usuários como usuários da informação envolvidos em busca ativa, enquanto analistas de sistemas tendem a vê-los como usuários de ferramentas interativas que melhoram sua performance (eficiência e eficácia) em tarefas humanas (que variam desde sistemas de informação para melhorar a produtividade no trabalho até aplicativos de entretenimento ubíquos). Esta diferença essencial na perspectiva de ambos profissionais - do usuário da informação envolvido em busca ativa até o usuário de produtos interativos (usuário interativo) - se reflete em suas metodologias de trabalho e mentalidades: a) bibliotecários abordam o usuário como uma pessoa que é interessada em conhecimento, cultura, armazenamento de dados, alguém que inspira cuidado (apesar do usuário potencial e do não usuário não receberem muita atenção deles); b) analistas de sistemas tem uma visão instrumental do usuário: eles são vistos como informantes para melhoria do design de produtos interativos feitos para cativá-los, e não exatamente como produsers, além de serem público potencial para uso de produtos interativos.

Já nas práticas profissionais de instituições arquivísticas, o usuário é usualmente denominado pesquisador, aquele que busca criar conhecimento, visão que se contrasta enormemente com usuários de sistemas de informação de analistas e, parcialmente, de bibliotecários, pois, à exceção de bibliotecas especializadas e universitárias, os usuários com que os bibliotecários lidam não são essencialmente produtores de conhecimento, mas usufruem dele.

Diferentemente da visão típica de bibliotecários, em que a terminologia público aparece timidamente na biblioteca pública, as instituições arquivísticas exercem trabalho com seu público - tido como público escolar, de qualquer nível (do infantil à pós-graduação) e público de ações culturais. Tal visão de público se contrasta fortemente com a visão de público de sistemas de informação, essencialmente público consumidor, mas se aproxima da percepção de público escolar de museus.

\section{PRÁTICAS DE MEDIAÇÃO}

A mediação pode ser vista, a grosso modo, como a interposição de um terceiro em alguma relação (DAVALLON, 2007), de maneira a transformá-la. A direção da transformação/ação do profissional em relação ao público e ao usuário, será diferente, portanto, para os profissionais. Se os profissionais bibliotecários, analistas de TI, e atuantes em instituições arquivísticas e museológicas concebem os usuários de maneira distinta entre si, conforme discutido na seção anterior, as relações que eles estabelecem com usuários e públicos também são diferentes. Dentre estas possíveis relações, ganham destaque as atividades de mediação formatadas por processos de mediação em eixos verticais (das relações societárias, da ordem do macro) e horizontais (das relações interepessoais, horizontais, da ordem do micro), conforme entendimento Perroti e Pieruccini (2014).

A mediação horizontal envolve atividades que aproximam usuários e públicos para que eles compreendam e usufruam de produtos, serviços, espaços, por meio de ações de cunho educativo ou instrutivo (mediação explícita); ou atividades que façam a tradução do universo simbólico dos usuários e públicos na elaboração de serviços e produtos ofertados pelos equipamentos e dispositivos informacionais e culturais (mediação implícita).

A mediação implícita envolve, no âmbito da biblioteca, centros de documentação, 
museus, a mediação documentária: documento e informação não são sinônimos. Considera-se que o documento se difere da informação e esta requer também trabalhos de mediação associados ao seu ciclo (produção, organização, disseminação e uso). Para Ortega $(2015$, p. 3) " [...] objetos tornam-se documentos por serem abordados informativamente". Desta maneira, as operações de gestão de documentos arquivísticos, tratamento da informação e musealização são ações de mediação documentária, e acontecem de maneira implícita (sem a presença do usuário). $\mathrm{O}$ ato mediador acontece sem a presença (física ou remota) do usuário/público/mediado e diz respeito à possibilidade de controle do profissional das possibilidades interpretativas do usuário ou do público, por meio da mediação dos signos (mediação semiótica/da linguagem). $\mathrm{O}$ mediador forma um modelo mental do seu usuário/público para ofertar serviços ou produtos (exemplos: criação de catálogos, planejamento de exposições, criação da linguagem de indexação, projeto de funcionalidades e interfaces de aplicativos).

No que diz respeito aos processos de mediação verticais, a atuação profissional diz respeito às funções sociais exercidas pelas instituições junto às coletividades. Pode se relacionar com mediação da memória, envolvendo processos de patrimonialização, musealização, produção cultural, entre outras. Também pode envolver a mediação social, inclusive por meio do papel das instituições na constituição da ordem social, como no cumprimento de políticas públicas, por exemplo. Destaca-se, neste eixo, a mediação cultural.

Perrotti e Pieruccini (2008) visualizam três vias para a mediação cultural, partindo das matrizes culturais para os regimes de institucionalidade: 1) a via da preservação e conservação cultural, em que as instituições são depositárias de objetos da cultura material ou promovem ações de animação cultural para conservar aspectos da cultura imaterial, por exemplo; 2) pela via da difusão cultural, em que a ação educativa pode cumprir papel essencial, possibilitando que manifestações culturais sejam assimiladas e perpetuadas no tecido cultural, sem envolver processos de criação do novo (aqui valem também processos de mediação horizontal e explícita); 3) pela via da facilitação ao processo de apropriação e criação cultural (fomento ao protagonismo cultural), sem antecipação de qualquer resultado. No último aspecto, na terceira forma de mediação cultural, é possível visualizar a mediação social que a instituição pode exercer, transformando a realidade social.

Algumas instituições têm papel protagonista na produção cultural, por se constituírem em instituições da indústria cultural, conforme seus formatos industriais (como os meios de comunicação de massa), outras não participam da lógica produtiva, não são indústrias culturais (como as bibliotecas e as instituições arquivísticas).

Cada vez mais os grandes meios de comunicação, e, especialmente, as mídias digitais e a internet, têm intermediado e mediado a produção cultural, um processo denominado por Martin-Barbero de mediatização (MARTIN-BARBERO, 2013). Os museus ocupam, nesse espaço, uma posição importante na produção cultural e são consideradas como mídia em si mesmas, diferentemente das instituições arquivo e biblioteca, o que lhe confere especificidades em suas práticas de mediação em relação às outras instituições. Tanto Lousada (2016) quanto Ortega (2015), quanto Martins (2010), concordarão que os processos envolvidos no ciclo documentário - produção do documento, organização e disseminação - são todos marcados pelas instituições biblioteca, arquivo e museu. Em outras palavras, há mediação em todo o ciclo documentário (mediação implícita na produção e organização do documento que pode e deve levar em conta os processos sociais e culturais que deram origem a ele; mediação explícita na disseminação), mas os processos de origem podem estar atrelados às ordens já estabelecidas pelas instituições na sociedade. A natureza dos documentos difere o papel da instituição (se biblioteca, arquivo ou museu) no âmbito da cultura. As instituições arquivísticas, por serem depositárias de documentos decorrentes de atividades administrativas, estão menos associadas às dinâmicas de produção cultural. Raciocínio análogo vale para a biblioteca, que, no limite, não agem como editoras. Já o museu é importante ator na produção cultural, tendo sido considerado mídia (TUCHERMAN; CAVALCANTI, 2010), e as instituições arquivísticas, ao produzirem publicações que podem servir de disseminadoras da História, 
realizando ações como exposições, também atuariam como produtoras de cultura.

As reflexões sobre o que é produzir cultura, na instituição museológica não encontram correlato nas outras áreas envolvidas no estudo (Arquivologia, Biblioteconomia, Sistemas Tecnológicos de Informação). As reflexões sobre o papel do museu na sociedade, como mediador da cultura são destacados em diversas falas, pelos profissionais de museus:

\begin{abstract}
[...] esse museu aqui ele é um museu e faz a diferença nessa cidade [...]. A gente criou um plano museológico, que atende a diversas [...] demandas da sociedade em termos de expectativa do que seja um museu, é um museu dinâmico [...] e democrático no sentido de que, a gente abriga várias tendências aqui da cultura, é um museu de arte contemporânea na sua natureza, e ele tem 5 missões especificas [Artes, Ciências, Cultura, Educação, Economia criativa... que] se desdobram em diretrizes [...] que trabalham desde as diversidade culturais [...] quem quiser contar a história da arte brasileira tem que obrigatoriamente passar por esse museu porque nós temos obras com valores culturais bem altos e valores pecuniários também que são patrimônio público muito importante aqui [M1].
\end{abstract}

Não apenas na fala de M1, mas dos outros entrevistados, o papel social do museu aparece destacado. Neste aspecto, a dimensão da mediação vertical, institucional, exercida pelo museu acontece de diversas maneiras. Um dos museus, pelo "simples" fato de existir em um bairro periférico, já transformou toda a dinâmica do bairro e passou a cumprir atividades quase extrainstitucionais, como realização de oficinas junto a instituições de reabilitação de usuários de drogas; outro promove concertos e música ao ar livre para atrair o público transeunte, outros colocam exposições ao ar livre para melhoria da relação com a comunidade do entorno.

$\mathrm{O}$ jogo dos atos mediadores $\mathrm{e}$ intermediadores realizados pelos atores sociais - indivíduos, organizações, movimentos sociais e culturais, atuadores - deve ser levado em conta em um quadro de referência macrossocial. É nessa direção que se torna importante pensar na obra de Barbero (2013).

O modelo de Martin-Barbero (2013) permite compreender a comunicação como mediadora de processos culturais. A organização de manifestações culturais, por exemplo, evidencia a existência de uma matriz cultural que se articula com o mundo do cotidiano, nas relações de socialidade dos membros de grupos (e aqui é possível que existam mediadores culturais, animadores culturais e educadores) e ações de mediação que mantenham a espontaneidade ou a vida cultural dos grupos. Uma vez que tais manifestações são apreendidas pelas atividades mediadoras dos meios de comunicação e outras instituições culturais (como os museus), a ação da institucionalidade (as ações de musealização; ou a instituição de políticas de formação de acervos e fundos em bibliotecas e arquivos; ou a institucionalização de movimentos sociais organizados diversos, por exemplo) requer a intencionalidade de mediadores no campo social e da cultura (como membros porta-vozes dos grupos e das instituições). A mediação da informação, por esse quadro conceitual, se associa aos processos de mediação documentária (quando se institui o documento diante dos processos sociais, portanto associada à institucionalidade) que ocorre tanto em dimensões implícitas da prática documentária quanto explícitas (ORTEGA, 2015; ALMEIDA JÚNIOR, 2009).

O social não está dado, mas é constantemente construído em trocas comunicativas cada vez mais mediatizadas: cada vez mais a realidade não é construída por relações interpessoais face a face, mas por relações constituídas por (inter)médio dos meios de comunicação de massa e por redes telemáticas. Os museus não escapam a este quadro e podem ser considerados atores que podem contribuir para a espetacularização da relação com a arte e a cultura, dão processo de mediatização da cultura, com suas implicações (MARTIN-BARBERO, 2013). Suas ações, especialmente as expositivas, podem pautar agendas culturais, artísticas, mediando produtores culturais e artistas com o grande público (mediação vertical).

Os equipamentos culturais e museológicos se colocam na dinâmica da produção cultural, na medida em que desenvolvem ações culturais que procuram valorizar a cultura local, por exemplo. Todos os entrevistados nos equipamentos culturais e museais dizem pautar exposições e eventos pelo calendário social, assim como o fazem vários arquivistas que promovem ações culturais. Pelo menos três 
entrevistados das instituições museológicas promovem eventos com danças típicas de sua região, com habitantes do local (os produtores, mediados pela instituição), que tanto atraem turistas como a população local, procurando preservar a cultura imaterial típica da cidade.

Uma das entrevistadas de um equipamento cultural disse adotar a técnicas de observação participante para compreensão e preservação de manifestação típica cultural de sua cidade, com auxílio da antropologia:

"me encantei, assim, pela pesquisa mesmo, pela relação com as pessoas que fazem cultura, que fazem arte, então, Antropologia me permitiu essa coisa de trabalho do campo, né?! da observação participante, dessa questão mais metodológica”. [M6].

A realização de inventários culturais, neste caso, tanto em seu produto como em seu processo são muito importantes nesta dimensão de mediação vertical. Também, neste caso, são realizadas pesquisas com o caráter da pesquisa-ação, neste mesmo equipamento:

\footnotetext{
"na ultima quarta-feira do mês uma série de pessoas, reunidas pra dialogar, discutir alguns temas especificos, né?! então também dependendo do mês, o tema é lançado, e muitas vezes lançado coletivamente também, o público que participa do observatório, diz: [...] vamos discutir sobre gênero, a participação das mulheres no carnaval [...]" [M6].
}

Há ações culturais (como concertos, exibição de filmes, espetáculos) que não dialogam com os acervos em diversas entrevistas, mas elas são justificadas como forma de melhorar as relações do público com o seu entorno, e também atrair o interesse para o museu ou para a instituição arquivística. Para uma entrevistada, as ações culturais bem sucedidas articulam as coleções do museu com os eventos:

"When we combine [...] the events with the collections [...] that is the most successful" [M7].

Uma das ações articuladas desta maneira seria exemplificada assim:

"ação cultural" a gente tenta implementar a cultura da preservação [...] do meio ambiente [...] estamos estruturando as nossas ações de uma maneira prévia pra poder "tá" implementando o ano do papagaio, levando em consideração que todo mundo quer ter um papagaio em casa. [...] Então a gente tá tentando desmistificar isso aí, mostrar que é crime, que para cada 9 animais é, para cada 10 animais capturados na natureza, 9 outros morrem só sobrevive 1 , que o impácto é grande no meio ambiente, que esse animal que faz parte numa cadeia ele tem a sua função, se ele for retirado dessa cadeia a piramide ela vai sofrer um, um impacto, pode haver um, um, um desequilibrio [M2].

Um museu de ciências, articulando com o seu espaço e com a comunidade, promove ações educativas que se relacionam com a pauta social, com a geração de renda:

nós temos programas sociais [...] são programas formativos aqui no museu: programa de iniciação ao mundo digital [em que] temos cursos de games, cursos de designer gráfico, curso de edição de vídeo; [e] projeto de jogos educativos em madeira, [com] o grupo da comunidade faz essa produção e além de vender em eventos que são coordenados pela nossa secretaria, [vende em] parceiros nossos como [...] shopping que tem aqui do lado [...] porque acaba gerando renda também [M5].

Por outro lado, a realização de oficinas (como oficinas de dança), uso do teatro/dramatização para aproximação do público das coleções, visitas guiadas são estratégias educativas de mediação horizontal, as que mais habitualmente se associam ao entendimento usual de mediação no campo da museologia. Muitos entrevistados deste campo relatam utilizar os referenciais teóricos do construtivismo (como de Piaget) para promover a aproximação do público com os objetos museais. Uma das técnicas é utilizar objetos desconhecidos e pedir que as pessoas, a partir de seus conhecimentos prévios, descubra o objeto. Há relatos muito sensíveis dos entrevistados neste processo de descoberta, que muitas vezes leva ao encantamento. A expografia tradicional às vezes é vista como problema para esta maior aproximação, e algumas tentativas com linguagens interativas e com multisensorialidade são apresentadas.

No que diz respeito às práticas de mediação do bibliotecário pesquisado (ROCHA, 2013), 
ele tem a responsabilidade de mediar a relação do usuário com os registros de conhecimento sob sua responsabilidade (ORTEGA Y GASSET, 2006). Com relação ao trabalho de mediação explícita, observa-se, no geral que: a) os bibliotecários de bibliotecas públicas e escolares se mostram atuantes nas ações de mediação explícita de ordem cultural (como a promoção da leitura), enquanto na biblioteca especializada tais ações não recebem tanta atenção quanto a disseminação seletiva, por exemplo; b) nas bibliotecas universitárias e também nas escolares, tem grande relevo as ações de letramento informacional e digital (auxílio ao usuário na localização de fontes, no uso de equipamentos digitais e normas bibliográficas, na elaboração de trabalhos escolares).

Já com relação aos trabalhos de mediação do analista de tecnologia da informação, notase que há diferentes perfis profissionais a lidar com usuários conforme a divisão das tarefas existente no mercado da tecnologia da informação. Há diferentes papeis profissionais que lidam com os usuários de sistemas de informação e produtos interativos: os que realizam trabalho de mediação implícita elaboram projetos de produtos interativos para os seus potenciais usuários - e aqueles que realizam trabalho de mediação explícita auxílio dos usuários no uso de produtos. De maneira sumária, o trabalho de mediação explícita é realizado por analistas de TI que têm a função de analistas de suporte (e analistas de negócio), os quais teriam a função de facilitar o uso dos sistemas e mediar modificações nele junto às equipes de analistas-desenvolvedores. As tarefas de conhecer as necessidades de usuários para elaboração de sistemas digitais (software) e produtos interativos - tarefas de mediação implícita - são divididas em dois perfis profissionais, basicamente: a) os designers de interação ou UX designers (User Experience Designers) são responsáveis por projetar as interações dos usuários com produtos interativos de qualquer natureza (desde interfaces de softwares para computadores desktop e interações humanas com dispositivos inteligentes e ambientes com computação ubíqua) e podem atuar em conjunto com arquitetos da informação (estes são responsáveis pela estrutura de navegação, rotulação, organização e busca da informação em variados ambientes digitais); b) os analistas de sistemas ou engenheiros de software são responsáveis pelos produtos de software (desde sua concepção, desenvolvimento e gestão), podendo existir subdivisões desta especialidade conforme o porte e a estrutura da empresa empregadora, como é o caso do perfil profissional específico do analista de requisitos computacionais (responsável pela concepção das soluções) (ROCHA, 2016a).

Os bibliotecários lidam com usuários que buscam conhecimento, enquanto os analistas de TI com trabalhadores e público consumidor de produtos interativos. De maneira geral, há afastamento no propósito nas ações de mediação dos profissionais - o bibliotecário auxilia a busca do conhecimento do seu usuário (leitor, trabalhador em busca de insumos informacionais), já o analista de TI projeta ferramentas para realização de alguma atividade cotidiana de maneira mais eficiente (trabalhador, público consumidor) e eventualmente dá suporte ao seu uso. Os profissionais arquivistas também destacam os processos de auxílio em busca-uso da informação, para criação de conhecimento, visão que não aparece problematizada na fala dos profissionais atuantes nos equipamentos culturais e museais.

No que diz respeito às práticas de mediação dos profissionais em instituições arquivísticas, o trabalho de mediação implícita envolve a organização dos documentos e também a produção de guias, verbetes, inventários, essenciais para o usuário e $\mathrm{o}$ atendente localizarem documentos. Este trabalho é semelhante ao realizado por bibliotecários ao criarem índices, resumos, listas de cabeçalho, ao lidarem com linguagens documentárias. Os desafios de tradução são semelhantes, embora, nas instituições arquivísticas o respeito aos princípios arquivísticos dificulte operações de tradução para o usuário, aspecto notado por todos os entrevistados, mas que não deve ser quebrado sob risco de não ser possível localizar nada também para atendê-lo. $\mathrm{Na}$ busca de solução, um dos entrevistados se culpa por sua instituição ter ido contra um dos princípios arquivísticos:

um dos princípios da Arquivologia a gente quebra um pouquinho que é a da ordem interna, [...] É claro que a gente sempre visa a recuperação da informação, visualiza o usuário. [...] Vou organizando de acordo com os parâmetros da arquivística. [...] A 
documentação é cheia de bolinha colorida [...] a gente chama isso de área. [...] O nosso arranjo não é funcional, é estrutural [...] tem alguns fundos que tem uma ligação muito forte entre si, então isso não foi eu que fiz, quando eu cheguei já estava assim, então tem [...] algumas áreas, enfim, que a gente foi notando que tem essa relação, [...] a gente foi anotando, por exemplo, [...] a área do judiciário com uma cor [...]. A gente foi relacionando os fundos com as áreas. Então, [a organização ficou] área - fundo - série - e o órgão! [...] Para facilitar a vida do atendente e facilitar a vida do pesquisador. (E5).

Já no que diz respeito às atividades de mediação explícita horizontais, os profissionais que atuam em instituições arquivísticas produzem formulários para serem preenchidos pelos usuários para solicitações, contendo campos que variam conforme a natureza da instituição e das solicitações. No geral, os dados se referem às características gerais demográficas (sexo, idade, escolaridade) e das consultas (documentos solicitados). São relatadas dificuldades semelhantes aos de bibliotecários para entender o que o usuário necessita ou a sua demanda, relativas à tradução para a linguagem documentária:

"Nós sabemos as vezes como é recuperar melhor uma informação na base, qual a palavra-chave usar, porque documentos de órgãos de segurança de informação eles têm uma linguagem bem especifica". (E3)

As atividades de atendimento do usuário, como as realizadas por setor de referência em bibliotecas ou salas de consulta de instituições arquivísticas, são semelhantes no sentido de desafiarem os profissionais a entenderem as necessidades e demandas dos usuários, envolvendo operações de tradução, manejo da linguagem, conversa, com suas dificuldades de compartilhamento do que está na mente do usuário (seus processos de semiose) para o profissional que o atende. As dificuldades são superadas, em parte, com bom conhecimento do acervo, pelos bibliotecários, e pelos fundos, pelos arquivistas. Já as dificuldades de compreensão das demandas, presentes nas atividades de referência de bibliotecários e arquivistas, são maiores no caso dos usuários de arquivos, pois a lógica dos fundos é menos intuitiva que a lógica dos registros bibliográficos. Existe maior dependência do usuário do Arquivo para suas consultas, desta atividade de mediação explícita para tradução das demandas, comparativamente ao usuário de biblioteca.

Visitas técnicas e realização de treinamentos voltados para estudantes universitários ou para servidores do governo, que aprofundam o entendimento dos princípios arquivísticos, são também práticas de mediação explícita que permitem fundar o espaço da instituição arquivística na sociedade. Bibliotecários e analistas de TI também realizam treinamentos voltados para apresentação de suas instituições e uso de recursos, em uma lógica transmissionista. Nota-se a problematização da importância do letramento informacional, da alfabetização digital, e do conhecimento da organização da instituição arquivística, mas a terminologia letramento é problematizada pelo bibliotecário, não pelos outros profissionais.

A interface arquivo-instituição escolar (uma das formas de mediação vertical, da presença da instituição arquivística na sociedade) é constituída por meio de visitas guiadas, oficinas de educação patrimonial voltadas para o público escolar, produção de material paradidático (para apoio ao ensino de história). Tais atividades se diferenciam das realizadas por bibliotecários e não encontram qualquer similar nas práticas dos analistas de TI, mas se aproximam das práticas realizadas pelos museus em interface com escolas.

Com relação às técnicas de educação patrimonial, os profissionais atuantes em instituições arquivísticas apresentam atividades culturais que relacionam documentos com a história da cidade, algumas delas envolvendo dramatização, aspecto que também foi observado nos museus. O emprego de caixas com objetos a serem descobertos/explorados também aparece nestas atividades para ambos os espaços museus e Arquivos.

Outro destaque, em relação às atividades de mediação das instituições arquivísticas em 
relação às bibliotecas, diz respeito às ações culturais. Tais ações são enumeradas pelos entrevistados arquivistas: exposições físicas e virtuais (sobre conteúdos históricos voltados para público escolar, história institucional, ou com mote ligado a datas comemorativas), projeto música no arquivo (para atrair a comunidade do entorno), seminários e palestras (sobre temas variados da história ou sobre os arquivos, tais como organização de arquivos pessoais). Dentre os bibliotecários que realizam ações culturais, destacam-se as rodas de leitura (em bibliotecas escolares e públicas) e eventos similares aos propostos pelos arquivos, embora não tenham sido relatadas realização de exposições por eles (ROCHA, 2013).

As instituições arquivísticas também se colocam como produtoras de documentos, com algumas delas editando revistas científicas e acadêmicas, e publicando materiais didáticos. Há interseção desta tarefa com o papel de pesquisa da instituição museológica. Esta atuação é de nível macro, horizontal. Não há correlatos destas atividades entre bibliotecários e analistas de TI estudados na tese (ROCHA, 2013).

Para todos os profissionais, a relação do usuário com a materialidade de dispositivos digitais (seja os presentes em exposições interativas, seja os do cotidiano), deve ser tomada como relevante. Existe uma dimensão de mediação técnica (como as relativas às habilidades com interfaces digitais, por exemplo) que deve ser levada em conta, mas que carece de ser mais bem estudada. $\mathrm{O}$ Quadro 1, sumariza as formas de mediação e suas práticas até aqui elencadas, e serve como aperitivo para o complexo estudo desta temática.

Quadro 1 - Práticas de mediação dos profissionais

\begin{tabular}{|c|c|c|c|c|c|}
\hline & Práticas & Bibliotecários & Analistas de TI & $\begin{array}{l}\text { Profissionais atuantes } \\
\text { em Arquivos }\end{array}$ & $\begin{array}{l}\text { Profissionais atuantes } \\
\text { em museus }\end{array}$ \\
\hline \multirow[t]{2}{*}{$\begin{array}{l}\text { Mediação } \\
\text { explícita } \\
\text { (Eixo } \\
\text { horizontal) }\end{array}$} & Ações educativas & $\begin{array}{l}\text { Rodas de leitura } \\
\text { Treinamento de } \\
\text { usuários } \\
\text { Visita guiada }\end{array}$ & $\begin{array}{l}\text { Treinamento de } \\
\text { usuários }\end{array}$ & $\begin{array}{l}\text { Treinamento de usuários } \\
\text { Educação patrimonial } \\
\text { (oficinas) } \\
\text { Visita guiada (diversos } \\
\text { segmentos escolares) }\end{array}$ & $\begin{array}{l}\text { Oficinas de educação } \\
\text { patrimonial } \\
\text { Visitas } \\
\text { (diversos guiadas } \\
\text { escolares ou turistas) }\end{array}$ \\
\hline & Atendimento & $\begin{array}{ll}\text { Atendimento } & \\
\text { presencial } & \\
\text { Atendimento } & \\
\text { remoto } & \\
\text { Serviço } & \text { de } \\
\text { referência } & \end{array}$ & $\begin{array}{l}\text { Suporte ao } \\
\text { usuário }\end{array}$ & Serviços de referência & \\
\hline \multirow[t]{5}{*}{$\begin{array}{l}\text { Mediação } \\
\text { explícita } \\
\text { (Eixo } \\
\text { vertical) }\end{array}$} & Ações culturais & $\begin{array}{lr}\text { Eventos } & \text { (como } \\
\text { eventos de música, } \\
\text { encontros } \\
\text { autor) }\end{array}$ & & $\begin{array}{l}\text { Exposições } \\
\text { Eventos (como eventos } \\
\text { de músicas, encontros } \\
\text { sobre temas históricos) }\end{array}$ & $\begin{array}{l}\text { Exposições } \\
\text { Eventos (como eventos } \\
\text { de música, encontros } \\
\text { com autor) }\end{array}$ \\
\hline & Seminários & & & $\begin{array}{l}\text { Seminários temáticos } \\
\text { (sobre Arquivos e } \\
\text { História). Pauta pode ser } \\
\text { calendário social. }\end{array}$ & $\begin{array}{l}\text { Seminários temáticos } \\
\text { (Pauta variável, pode } \\
\text { seguir o calendário } \\
\text { social) }\end{array}$ \\
\hline & $\begin{array}{l}\text { Produção de } \\
\text { publicações ou de } \\
\text { sistemas }\end{array}$ & & $\begin{array}{l}\text { Aplicativos } \\
\text { digitais }\end{array}$ & $\begin{array}{l}\text { Anais dos Arquivos, } \\
\text { revistas científicas, } \\
\text { revistas dos Arquivos }\end{array}$ & $\begin{array}{l}\text { Revistas e seminários } \\
\text { científicos }\end{array}$ \\
\hline & Pesquisa-ação & & & & $\begin{array}{l}\text { Mediação cultural } \\
\text { Diálogos com } \\
\text { produtores culturais } \\
\text { para formatação de } \\
\text { ações coletivas. }\end{array}$ \\
\hline & Programas sociais & & & & Mediação cultural \\
\hline
\end{tabular}




\begin{tabular}{|c|c|c|c|c|c|}
\hline & & & & & $\begin{array}{l}\text { Inclusão produtiva } \\
\text { (economia solidária) } \\
\text { Ações com as } \\
\text { comunidades } \\
\text { Encaminhamento de } \\
\text { políticas públicas da } \\
\text { cultura }\end{array}$ \\
\hline & Agenda da cultura & & & & $\begin{array}{l}\text { Mediação cultural } \\
\text { Inserção de atividades } \\
\text { na dinâmica coletiva } \\
\text { Risco de } \\
\text { espetacularização }\end{array}$ \\
\hline \multirow[t]{2}{*}{$\begin{array}{l}\text { Mediação } \\
\text { implícita }\end{array}$} & $\begin{array}{l}\text { Mediação } \\
\text { implícita }\end{array}$ & 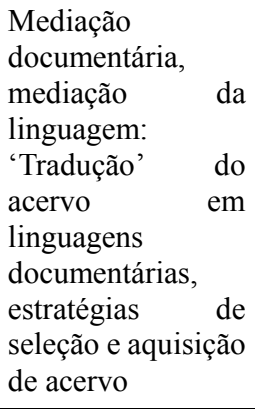 & \begin{tabular}{|lr} 
Design & de \\
sistemas & $\mathrm{e}$ \\
interfaces & \\
(Mediação & $\mathrm{da}$ \\
linguagem) & \\
& \\
& \\
&
\end{tabular} & $\begin{array}{l}\text { Mediação documentária } \\
\text { Arranjo, gestão de } \\
\text { documentos }\end{array}$ & $\begin{array}{l}\text { Projetos expositivos, } \\
\text { processos } \\
\text { patrimonialização } \\
\text { musealização } \\
\text { (Envolve mediação } \\
\text { documentária e da } \\
\text { linguagem) }\end{array}$ \\
\hline & Medição técnica & \multicolumn{4}{|c|}{$\begin{array}{l}\text { Restrições das materialidades da relação do usuário com documentos, aplicativos, } \\
\text { exposições, dispositivos técnicos e digitais }\end{array}$} \\
\hline
\end{tabular}

Fonte: Dados da pesquisa

Nota-se, no Quadro 1, que todos os profissionais desenvolvem ações de mediação implícita, ligado ao trabalho de tradução de linguagens técnicas para os usuários $\mathrm{e}$ públicos, além de precisarem endereçar a problemática das mediações técnicas, que dizem respeito aos próprios formatos dos documentos, sistemas ou instituições sob sua responsabilidade. Além disso, todos estão envolvidos com ações explícitas de educação ou treinamento de usuários e públicos, na relação sincrônica com os mesmos (atividades de mediação explícita no eixo horizontal). Já as atividades de mediação vertical, que requerem trabalho das instituições em dinâmicas sociais e culturais diacrônicas (mediação explícita, eixo vertical) estão essencialmente presentes nas práticas de profissionais atuantes em museus (pois estes são equipamentos culturais e produtores de cultura) e de analistas de tecnologia da informação (se se considera que aplicativos computadorizados são produtos culturais), e de maneira subsidiária em instituições arquivísticas, como resultante de seus processos de difusão.

\section{CONSIDERAÇÕES FINAIS}

Tendo em vista o objetivo de apresentar como os profissionais atuantes em bibliotecas, instituições arquivísticas e museológicas, além de analistas de tecnologia da informação, tem abordado seus usuários e públicos em suas práticas de trabalho, afirma-se que todos os profissionais abordam usuários e públicos por meio de práticas de mediação, com diferentes nuances.

As práticas de mediação relativas ao atendimento para prestação de serviços de referência e suporte a usuários de aplicativos requerem habilidades de conhecimento do acervo e dos fundos, além da necessidade de bom trabalho anterior de organização dos documentos (relacionados às atividades de mediação implícita). Também a boa habilidade de conversação para tradução da demanda do usuário e bom trato pessoal (destacado pela necessidade de ser paciente destacada por bibliotecários e analistas de $\mathrm{TI}$ ) devem ser desenvolvidos.

Já nas práticas de mediação implícita, é muito difícil pensar em uma proposta teóricometodológica comum entre os profissionais envolvidos, pois elas são muito diversificadas e extremamente contrastantes: as linguagens de tradução envolvidas (linguagens documentárias, linguagens expositivas, interfaces de aplicativos) são muito distintas para os profissionais, sendo muito difícil promover o diálogo entre as áreas.

Por meio da análise de conteúdo das entrevistas realizadas, comparadas ao trabalho 
anterior (ROCHA, 2013), é possível afirmar que as práticas de mediação cultural são realizadas e problematizadas sobretudo pelos profissionais atuantes em museus, enquanto que as práticas de mediação informacional e documentária, enfatizadas por bibliotecários e arquivistas. Já as práticas de mediação de analistas de sistemas se distanciam da discussão das práticas de mediação cultural e documentária, prevalecendo a discussão sobre os processos da mediação da linguagem/negociação de significados relativos aos processos de construção de sistemas. As práticas de mediação explícita de treinamento de usuários estão presentes nas práticas de analistas de sistemas, bibliotecários, arquivistas, mas não são alvo de práticas de museólogos, em que as ações de mediação explícita são organizadas por ações educativas e culturais.
Tendo em vista que o conceito de mediação é multifacetado, e que as atividades profissionais são muito diversificadas, este trabalho apresentou uma visão panorâmica das práticas de mediação relativas aos usuários pelos profissionais, possibilitando apresentar a importância destacada das práticas de mediação explícita e culturais para os profissionais atuantes em instituições museológicas em relação aos demais profissionais; a presença de ações educativas e de treinamento que precisam ser ancoradas em referenciais teórico-metodológicos do campo educacional; a realização de atividades de mediação implícita de alta complexidade conforme as instituições, públicos e usuários envolvidos. No entanto, é necessário, em trabalhos futuros, explorar as especificidades de cada forma de mediação para cada profissional. A operação panorâmica foi realizada, agora, é preciso efetuar o zoom-in.

\title{
PUBLIC AND USERS IN INFORMATION PROFESSIONS' PRACTICES AND CORRELATED AREAS
}

\begin{abstract}
This paper aims to present how professions in Libraries, Archival and Museum Institutes, and Information Technology professionals has been approaching their users in their work practices. It was accomplished bibliographic review on their work practices, and a field research evolving interviews with six professionals in Archival institutes and other seven in Museum institutes. Through content analysis of those interviews compared to previous bibliographic review, it is concluded that all professionals approach users through mediation practices with different nuances. It is possible to afirm that cultural mediation practices are problematized and done by museum professionals, while documentary and information medition are enphatized by librarians and archivists. Mediation practices of information technology professionals are far from discussing cultural and documentary mediation practices, prevailing the discussion of language/meaning negotiation implicated in builinding automated systems. The user trainning explicit mediation practices are present in systems analysts, librarians and archivists, but are not the aim of museum professionals, in which explicit mediation actions are done through educative and cultural actions.
\end{abstract}

Palavras-chave: Mediation; Archivist; Librarian; Museologist; System Analyst; User; public. 


\section{REFERÊNCIAS}

ARAÚJO, C. A. A. O que são "práticas informacionais"? Inf. Pauta, Fortaleza, CE, v. 2, número especial, out. 2017

ALMEIDA JÚNIOR, O. F. Mediação da informação e múltiplas linguagens. Pesq. bras. Ci. Inf., Brasília, v.2, n.1, p.89-103, jan./dez. 2009.

CAPURRO, R. Epistemologia e Ciência da Informação. In: ENCONTRO NACIONAL DE PESQUISA EM CIÊNCIA DA INFORMAÇÃO, 5., 2003. Anais... Belo Horizonte: ANCIB, 2003. Disponível em <http://www.capurro.de/enancib_p.htm> Acesso em jun 2015.

COSTA, Igor Cândido; ROCHA, Eliane Cristina de Freitas Rocha. A mediação na Museologia e na Ciência da Informação. In: ENCONTRO DE MUSEOLOGIA DA UNIVERSIDADE DE BRASÍLIA, 1., 2018. Anais... Brasília: UNB, 2018. [No prelo]

CUNHA, Murilo Bastos da; AMARAL, Sueli Angélica; DANTAS, Edmundo Brandão. Manual de estudos de usuários da informação. São Paulo: Atlas, 2015.

DAVALLON, J. A mediação:a comunicação em processo? Prisma.Com: revista de Ciência da Informação e da Comunicação do CETAC, n.4, p.1-34, jun.2007. Disponível em << http://revistas.ua.pt/index.php/prismacom/arti cle/viewFile/645/pdf>> Acesso em set. 2016.

GUARESCHI, P. A. Relações comunitárias relações de dominação. In: CAMPOS, R. H. F. Psicologia social comunitária: da solidariedade à autonomia. 15 ed. Petrópolis, RJ: Vozes, 2009.

KÖPTCKE, L. S. Público, o X da questão? A construção de uma agenda de pesquisa sobre os estudos de público no Brasil. Museologia \& Interdisciplinaridade: Revista do Programa de Pós-Graduação em Ciência da Informação da Universidade de Brasília. v.1, jan/jul 2012.

LOUSADA, M. A mediação da informação e a arquivologia: aproximações teóricas. Pesq.

Bras. em Ci. da Inf. e Bib., João Pessoa, v.11, n. 1, p. $117-134,2016$.
MARTÍN-BARBERO, J. Dos meios às mediações - comunicação, cultura e hegemonia. [1987] 7. Ed. Rio de Janeiro: UFRJ, 2013. 356p.

MARTINS, A. A. Mediação: reflexões no campo da Ciência da Informação. 253f. (Dissertação de Mestrado) - Programa de PósGraduação em Ciência da Informação. Escola de Ciência da Informação da Universidade Federal de Minas Gerais. 2010.

MOREIRA, F. J. M. Uma reflexão sobre o conceito de público nos museus locais. Musas, Rio de Janeiro, n. 3, p.101-108, 2007.

OLIVEIRA, Gustavo Augusto Andrade de; ROCHA, Eliane Cristina de Freitas. A mediação em Arquivos: o estado da arte em periódicos de língua inglesa. 2018. [Artigo enviado para avaliação de periódico].

ORTEGA, C. D. Da mediação em Ciência da Informação. 2015. 121f. (Relatório final de pesquisa de pós-doutoramento). Programa de Pós-Graduação em Ciência da Informação. Universidade Federal Fluminense - UFF, Niteroi, Rio de Janeiro, 2015.

PERROTTI, E.; PIERUCCINI, I. Infoeducação: saberes e fazeres da contemporaneidade. In: LARA, M. L. G; FUJINO, A; NORONHA, D. P. (Orgs.). Informação e contemporaneidade: perspectivas. Recife: Néctar, 2008. p. 46-97.

PERROTTI, E.; PIERUCCINI, I. A mediação cultural como categoria autônoma. Inf. Inf., Londrina, v. 19, n. 2, p. 1-22, maio/ago. 2014.

ROCHA, Eliane Cristina de Freitas. Usuário da informação, um velho (?) (des)conhecido: usuários da informação em diferentes profissões da informação. $364 \mathrm{f}$. 2013. Tese (Doutorado em Ciência da Informação) - Universidade Federal de Minas Gerais, Escola de Ciência da Informação.

ROCHA, E. C. F. Information Users X Interactive Users: Different Subjects Challenging Different Information Professionals. ATINER'S Conference Paper Series, No: LIB2015-1815. Athens: ATINER, 2016a. 
ROCHA, E. C. F. Usuários e arquivos: problematizando as mediações. In: SIMPÓSIO TEMÁTICO ARQUIVOS \& EDUCAÇÃO, 1 , 2016, Fortaleza.

PARRELA, I. D.; KOYAMA, A. C. (Orgs.) Arquivo e educação: experiências e pesquisas brasileiras em diálogo. Belo Horizonte: Escola de Ciência da Informação, Programa de Pósgraduação em Ciência da Informação, 2016b.
Comunicação, mídia e consumo, v.7, n.20, p. 141-158, 2010.

ZAGO, Andréa do Prado; WADA, Elizabeth Kyoko. Dinâmica de stakeholders e cocriação de valor em museus: um olhar inicial. Revista Ibero Americana de Estratégia. 2013. Disponível em: $<$ http://www.redalyc.org/articulo.oa?id=3 $\underline{31228859010}>$ Acesso em nov. 2018

TUCHERMAN, I.; CAVALCANTI, C. C. B.

Museus: dispositivos de curiosidade. 